\title{
Early Life Stress Affects Mortality Rate More than Social Behavior, Gene Expression or Oxidative Damage in Honey Bee Workers
}

Olav Rueppell ${ }^{\$}$, Babak Yousefi ${ }^{\mathrm{a}}$, Juan Collazo ${ }^{\mathrm{a}}$, Daniel Smith ${ }^{\mathrm{a}}$

${ }^{a}$ Department of of Biology, 312 Eberhart Building, The University of North Carolina at Greensboro, 321 Mclver Street, Greensboro, NC 27402, USA.

\$ Corresponding Author: Email: olav_rueppell@uncg.edu, Phone: (+1) 336-2562591, Fax: (+1) 336-3345839 


\section{Abstract}

Early life stressors can affect aging and life expectancy in positive or negative ways. Individuals can adjust their behavior and molecular physiology based on early life experiences but relatively few studies have connected such mechanisms to demographic patterns in social organisms. Sociality buffers individuals from environmental influences and it is unclear how much early life stress affects later life history. Workers of the honey bee (Apis mellifera L.) were exposed to two stressors, Varroa parasitism and paraquat exposure, early in life. Consequences were measured at the molecular, behavioral, and demographic level. While treatments did not significantly affect levels of oxidative damage, expression of select genes, and titers of the common deformed wing virus, most of these measures were affected by age. Some of the age effects, such as declining levels of deformed wing virus and oxidative damage, were opposite to our predictions but may be explained by demographic selection. Further analyses suggested some influences of worker behavior on mortality and indicated weak treatment effects on behavior. The latter effects were inconsistent among the two experiments. However, mortality rate was consistently reduced by Varroa mite stress during development. Thus, mortality was more responsive to early life stress than our other response variables. The lack of treatment effects on these measures may be due to the social organization of honey bees that buffers the individual from the impact of stressful developmental conditions.

\section{Keywords}

Developmental stress; Parasitism; Pesticide; Predictive behavioral demography; Social evolution 


\section{Introduction}

Early life influences profoundly impact biological systems in later life. Such effects include adaptive developmental plasticity that modifies developmental programs according to early cues in anticipation of the adult environment (Beldade et al., 2011). Anticipatory mechanisms range from molecular and physiological changes to morphological and behavioral adjustments and can occur even in eusocial insects where the colony buffers most external environmental fluctuations (Wang et al., 2016a). Early life influences may also negatively impact later life performance, either as a consequence of maladaptive plasticity when developmental cues do not match the adult environment (Gluckman et al., 2005) or in the form of persistent, sublethal stress effects (Desneux et al., 2007). In a number of species early life experiences can have dramatic consequences for later-life behavior, physiology, health and mortality risk [e.g. (Colborn et al., 1993; Hales and Barker, 2001; Roseboom et al., 2006)].

In social organisms, early life stages are shielded from many environmental insults. Emergent group functions, such as the construction of sophisticated homes, cooperative defense, and brood care, result in juvenile development in homeostatically controlled environments. This is particularly true for the eusocial, nest-constructing insects (Turner, 2009; Wilson, 1971), including honey bees (Winston, 1987). Societies of the Western Honey Bee (Apis mellifera L.) contain thousands of functionally sterile workers that build and maintain a wax nest inside a protected cavity, tightly regulate nest climate, care for the developing brood, and forage for nectar and pollen resources to provision the colony. Typically, honey bee workers perform their tasks in an agedependent manner (Winston, 1987). The transition from in-hive tasks to outside foraging 
in older workers constitutes a major life history transition, affecting individual mortality risk and nutrient balance of the colony (Rueppell et al., 2007). Premature foraging can cause colonies to collapse via demographic feedback loops (Perry et al., 2015). Eggs produced by a sole reproductive queen develop into larvae that grow and mature rapidly (Winston, 1987), presumably due to the intense care of their worker sisters and the protected hive environment.

Nevertheless, young honey bees are exposed to numerous stressors, as highlighted by recent studies of declining honey bee health. Some of the most relevant stressors that have been identified are nutrition (Huang, 2012), pesticides (Mullin et al., 2010), and diseases (Kielmanowicz et al., 2015). In many instances, these stressors do not kill individuals directly but exert sublethal effects that make individuals more susceptible to other factors. A number of such interaction effects have been documented (Alaux et al., 2010; Pettis et al., 2012; Sánchez-Bayo et al., 2016). Thus, sublethal effects of early life stressors are important for understanding honey bee health.

One of the most important causes of declining honey bee health is the ectoparasitic mite Varroa destructor (Rosenkranz et al., 2010, Dietemann et al., 2012). Varroa parasitism causes reduced learning capabilities (Kralj et al., 2007) and premature foraging and death (Janmaat and Winston, 2000) in worker honey bees. However, the long-term interactions between early life stress, overall behavioral profiles, and mortality have not yet been sufficiently characterized. More generally, honey bee workers can serve as social models to investigate the persistence of early sublethal stress at multiple levels of biological organization. In particular, social interactions and 
behavior, which are central to aging and mortality (Amdam, 2011) but not often addressed in an experimental context, are quantifiable under natural conditions. In this study, honey bee workers were exposed separately to two independent stressors early in life and subsequently compared to controls with regards to expression levels of select transcripts, oxidative damage, life-long behavior profiles, and mortality.

\section{Materials and Methods}

Several experimental colonies of mixed European descent in the UNCG bee yard were used as source colonies for two independent experiments to study the effects of early life stress on later life in worker honey bees.

\subsection{Demographic Varroa Experiment}

The survival and lifetime behavioral profiles of two groups of worker honey bees were compared. Developing larvae were either not manipulated (control group) or experimentally infected with an ectoparasitic Varroa destructor mite (Varroa group). Varroa mites complete their reproductive cycle on the developing honey bee larvae in closed (capped) wax cells (Rosenkranz et al., 2010). Varroa exerts stress by feeding on the honey bees' hemolymph (De Jong et al., 1982) and by vectoring and facilitating a number of honey bee viruses (Genersch and Aubert, 2010; Kuster et al., 2014; Martin et al., 2012).

Four frames with $5^{\text {th }}$ instar brood were collected in May 2013 and the position of cells that were not yet capped was marked on a transparent sheet (Kuster et al., 2014). These frames were immediately returned to their colonies and rechecked after 12 hours. Approximately 120 experimental $V$. destructor mites were introduced into cells 
that had been newly capped and the remaining newly capped cells were left intact as controls. Mature female $V$. destructor mites were collected in their phoretic phase from unrelated honey bee hives by the "sugar shake" method (Dietemann et al., 2013) and cleaned with a moist paintbrush before introducing them into brood cells (Kuster et al., 2014). The frames with Varroa infested and control cells were returned to their colonies for ten days before being transferred into an emergence incubator $\left(33^{\circ} \mathrm{C}, 65 \%\right.$ rel. hum.). After emergence began, frames were continuously monitored for 72 hours and emerging workers were sorted into parasitized and non-parasitized individuals based on the presence or absence of Varroa mites on their body or in the respective brood cell.

Newly emerged workers were individually marked with colored plastic tags (Dixon et al., 2014; Rueppell et al., 2007). Marked workers were introduced within 24 hours of emergence into a four-frame observation hive that had been established two weeks prior with a queen, 3000 workers of mixed ages, one frame of brood, and pollen and nectar resources. Small puffs of smoke accompanying the introduction of the experimental workers reduced their rejection by the host colony, and we further minimized the number of ejected workers by blocking the entrance for 12 hours after introduction. Introductions were made over a 2-day period as emerging workers were collected. Behavioral observations of individuals that survived the introduction $\left(\mathrm{n}_{\text {control }}=\right.$ $\left.162, \mathrm{n}_{\text {mite }}=71\right)$ were initiated within 24 hours.

Daily behavioral observations over 10 hours each day followed a previously established scan-sampling protocol (Dixon et al., 2014) with 24 defined behaviors that were consolidated in subsequent analyses to 14 behavioral categories (Table 1). Individuals were recorded as dead one day after their last observation because honey 
bee workers return to their hives as long as they live. The timing of the transition from in-hive tasks to outside foraging [=age of first foraging: AFF (Rueppell et al., 2007)] was recorded as the day at which the first record of "foraging", or "dance" was detected.

\subsection{Demographic and Molecular Varroa and Paraquat Experiment}

The second experiment was conducted in June 2013 similarly to the first, except for the following modifications. In addition to the Varroa and control groups, a third group exposed to the oxidative stress-inducing pesticide paraquat was studied. Paraquat (N,N'-dimethyl-4,4'-bipyridinium), was developed as a herbicide and is commonly used to induce oxidative stress in a variety of organisms (Bus and Gibson, 1984), including honey bees (Seehuus et al., 2006b; Corona et al., 2007). Workers that emerged without Varroa infestation were either left as controls or subjected to a topical application of $1 \mu \mathrm{l}$ of a $10 \mu \mathrm{g} / \mu \mathrm{L}$ aqueous paraquat solution, resulting in $\mathrm{n}_{\text {control }}=143$, $\mathrm{n}_{\text {mite }}=83, \mathrm{n}_{\text {paraquat }}=160$ over 5 days.

Workers from all treatment groups were sampled 8 days after the initiation of the experiment (age: $3-8$ days) and when the experiment was terminated after 28 days (age: $23-28$ days) to survey the expression of select transcripts and compare oxidative stress damage among the groups. Workers were directly sampled from the hive into liquid nitrogen and later transferred to a $-80^{\circ} \mathrm{C}$ freezer until analysis. The young cohort $\left(n_{\text {control }}=13, n_{\text {mite }}=7, n_{\text {paraquat }}=14\right)$ was randomly collected from the center of the brood nest, the older cohort $\left(n_{\text {control }}=23, n_{\text {mite }}=7, n_{\text {paraquat }}=15\right)$ represented all workers alive at the end of the experiment. 
Relative levels of seven molecular targets in the abdomen of the sampled individuals were determined by quantitative PCR. The abdomen contains the majority of the fat body of adults and thus is highly relevant for immune and detoxification functions. The level of the common, often latent deformed wing virus (DWV) (Genersch and Aubert, 2010) and the gene expression levels of vitellogenin, superoxide dismutase (SOD-1), catalase, microsomal glutathione S-transferase-1 (mGST1), prophenol oxidase activator (PPOact), and hymenoptaecin were quantified. Vitellogenin is a yolk precursor that is also important in endocrine regulation (Guidugli et al., 2005), related to immunity (Amdam et al., 2005), and acts as an antioxidant (Corona et al., 2007; Seehuus et al., 2006b). SOD-1, mGST1, and catalase are important detoxification enzymes of oxidative stress (Corona and Robinson, 2006), and PPOact and hymenoptaecin constitute two different immune effector genes (Evans, 2006). Actin was selected as reference gene to standardize the data (Cornman et al., 2012; Scharlaken et al., 2008).

Total RNA was extracted by standard Trizol ${ }^{\mathrm{TM}}$ (Life Technologies, Carlsbad, CA, USA) extraction from individual abdomens, quantified with a Nanodrop ${ }^{\mathrm{TM}}$ spectrophotometer (Thermo Fisher Scientific, Waltham, MA, USA), diluted to $500 \mathrm{ng} / \mu \mathrm{L}$ and stored at $-80^{\circ} \mathrm{C}$. Total RNA was used after DNAse treatment for cDNA synthesis, using the SensiFAST kit (Taunton, MA, USA) according to the manufacturer's recommendations with a mixture of random hexamer and poly-dT priming (Boncristiani et al., 2013; Kuster et al., 2014). The resulting cDNA was used as template for individual, $20 \mu \mathrm{l}$ qPCR assays of the target transcripts using the Power SYBR Green ${ }^{\mathrm{TM}}$ Master Mix (Applied Biosystems, Warrington, UK) according to the manufacturer's 
recommendations with specific primers (Table 2). Reactions were run on a StepOnePlus ${ }^{\mathrm{TM}}$ (Applied Biosystems) thermocycler, starting with three minutes at $95^{\circ} \mathrm{C}$, then 40 cycles of $95^{\circ} \mathrm{C}$ for 20 seconds, $60^{\circ} \mathrm{C}$ for 30 seconds, $72^{\circ} \mathrm{C}$ for one minute, and $72^{\circ} \mathrm{C}$ for another 20 seconds during which fluorescence measurements were taken. $\mathrm{A}$ final melt curve determination was conducted at the end.

Fluorescence thresholds were automatically determined with the StepOnePlus algorithmic threshold search across each plate and template to calculate Ct values for each reaction. Reactions were performed in triplicate and $\mathrm{Ct}$ values averaged. $\mathrm{Ct}$ values of the reference gene were also averaged across technical replicates for each sample and used to standardize the target genes. Transcripts of specific samples that consistently failed to amplify across all three technical replicates and two independent cDNA syntheses were coded as $\mathrm{Ct}=40$ to indicate very low transcript abundance (Pabinger et al., 2014). Cases in which the reference reactions did not yield any product resulted in the exclusion of the corresponding sample from the analysis. The relative expression levels were expressed as $\Delta \mathrm{Ct}=\mathrm{Ct}($ reference gene $)-\mathrm{Ct}($ target gene $)$, so that a high $\Delta \mathrm{Ct}$ value reflects a high relative gene expression (Evans, 2006; Kuster et al., 2014; Scharlaken et al., 2008).

Oxidative damage was measured in the thorax by quantifying thiobarbituric acid reactive substances (OXItek ${ }^{\text {TM }}$ TBARS assay; ZeptoMetrix Corp, Buffalo, NY). The frozen thorax was directly pulverized in a cooled microcentrifuge tube, thoroughly mixed with $280 \mu \mathrm{L}$ of PBS, and briefly centrifuged to precipitate large tissue and cuticle parts. The supernatant was aliquoted to conduct a Pierce BCA ${ }^{\text {TM }}$ Protein Assay kit (Thermo Scientific) and the TBARS assay, both according to the manufacturers' 
recommendations. Standard curves were determined to compute assay values from the spectrophotometric readings. The TBARS values were standardized for the total amount of tissue in each sample by division with the BCA value.

\subsection{Analyses}

To avoid experimental artefacts, individuals with a lifespan $<5$ days or with only a single behavioral observation were excluded from the analyses. Mortality and the age of first foraging were compared among the treatment groups by log-rank test as implemented in the Survival Analysis module of SPSS Statistics 21 (IBM, Armonk, NY). Behavioral observations were standardized by dividing the number of observations in each behavioral category (Table 1) by the total number of behavioral observations for each individual. The miscellaneous category "Patrolling" was omitted from multivariate analysis to avoid data singularity but it was included in the independent tests of single variables. The influence of the experimental treatments on social behavior was measured overall by MANOVA of the relative behavioral frequencies, followed by separate ANOVAs for each variable. Next, the simultaneous assessment of experimental treatment and lifetime behavior of individuals on mortality risk was performed by Cox-proportional hazard estimation (stepwise backward regression with an exclusion probability of 0.10 ). To test the predictive power of behavioral profiles at young ages for subsequent mortality, the Cox regression was repeated with behavioral frequencies determined only between days 1 and 15 and restricting the analysis to individuals that lived at least 16 days. The effects of age, treatment, and their interaction on relative gene expression values $(\Delta \mathrm{Ct})$ and standardized TBARS were evaluated by two-factorial ANOVAs. 


\section{Results}

\subsection{Demographic Varroa Experiment}

In the first experiment, the probability to survive the initial four days was not significantly different (Fisher's exact $p=0.693$ ) between the Varroa $(95.1 \%)$ and control (96.7\%) groups. Life expectancy estimates for the remaining individuals were low but significantly $\left(X^{2}=10.1, p=0.001\right)$ higher in the control group with an average of 15.4 (95\% confidence interval: $14.3-16.6, n=137$ ) than in the Varroa group with an average of $12.0(10.4-13.7, n=52)$ (Figure 1$)$. The age of first foraging (AFF) was correspondingly higher $\left(X^{2}=4.3, p=0.038\right)$ in the control group with an average of 13.6 $(12.4-14.7, \mathrm{n}=65)$ than in the Varroa group with an average of $11.5(10.3-12.7, \mathrm{n}=$ 18) (Figure 1 insert).

The treatment had a minor impact on behavioral measures that was not significant overall (Pillai's Trace $=0.12, F_{(1,187)}=1.7, p=0.056$ ). Analyzed separately, "ventilation" was twice as commonly recorded in the Varroa (0.056 \pm 0.12 S.D.) than in the control group $(0.028 \pm 0.05)$ and "runway" was more common in the control $(0.14 \pm$ $0.12)$ than in the Varroa group $(0.095 \pm 0.12)$. Both differences were significant ("ventilation": $F_{(1,187)}=4.9, p=0.028$ and "runway": $\left.F_{(1,187)}=4.0, p=0.046\right)$.

The combined analysis of treatment and lifetime behavioral profile effects on mortality risk confirmed the increase of mortality due to Varroa mite stress and suggested that foraging-related activities decreased mortality, while relatively more "brood care", "comb building", "ventilation", "resting", and "grooming" increased mortality (Table 3). When the impact of behavior between days 1 and 15 on subsequent mortality 
was assessed, only "dance" exhibited a significant effect, increasing mortality (hazard ratio $=2.4 \times 10^{9}, \mathrm{n}=62, \mathrm{p}=0.003$ ).

\subsection{Demographic and Molecular Varroa and Paraquat Experiment}

In the second experiment, the probability to survive the first four days and thus to be included in the analysis differed significantly among treatment groups $\left(X^{2}=12.7, p=\right.$ 0.002): The paraquat group exhibited the lowest initial survival (59.9\%), followed by the Varroa (76.6\%) and the control group (78.2\%). Life expectancy in the remaining individuals (Figure 2) was highest for controls [15.4 (13.5 - 17.4), $\mathrm{n}=104]$, followed by paraquat exposed workers [14.8 $(12.5-17.1), \mathrm{n}=82]$ and the Varroa mite parasitized individuals [11.5 (9.1 - 13.9), $\mathrm{n}=59$ ], although the differences were not quite significant $\left(X^{2}=5.9, p=0.051\right)$. Records of foraging-related activities were very low in the second cohort, preventing a meaningful analysis of the AFF due to small sample sizes (Control: $\mathrm{n}=19$, Varroa: $\mathrm{n}=6$, and Paraquat: $\mathrm{n}=14$; Figure 2 insert).

The treatments did not significantly affect overall behavioral measures (Pillai's Trace $=0.12, F=1.1, p=0.356$, all ANOVAs: $\left.F_{(2,242)}<2.3, p>0.1\right)$. The analysis of combined effects of treatment and behavior on mortality risk revealed that Varroa mite stress, but not paraquat, significantly increased mortality risk (Table 3). Additionally, the relative frequency of "nectar processing" increased mortality, while "comb building", "resting", "runway", and foraging-related activities decreased mortality risk (Table 3). The only behavior that was observed in the first two weeks of life to have a significant effect on subsequent mortality was "runway" (hazard ratio $=2533, n=85, p=0.002$ ).

The expression of transcripts was mostly affected by age but not treatment (Table 4). Levels of catalase and mGST1 increased with age, while transcript levels for 
DWV, prophenol oxidase activator, and vitellogenin were significantly lower in old than young individuals (Figure 3). Oxidative damage measures in the thorax were not significantly affected by treatment $\left(F_{(2,34)}=0.9, p=0.436\right)$ but they declined with age $\left(F_{(1,34)}=6.6, p=0.015\right)$ without an interaction between the two factors $\left(F_{(2,34)}=0.2, p=\right.$ 0.645). The lower ratio of TBARS to BCA values in old individuals was not due to higher overall protein levels because older workers exhibited lower BCA levels than younger workers $\left(F_{(1,34)}=7.9, p=0.008\right)$.

\section{Discussion}

Among the multiple responses to early life stress measured in this study, only mortality risk was significantly and consistently affected. This overall result suggests that life expectancy and mortality dynamics represent sensitive measures of stress exposure. Experimental treatments also resulted in some behavioral changes in subsequent adult life but these changes were minor and not consistent among the experiments. Neither of the two stressors led to persistent changes in oxidation of lipids or levels of seven a-priori selected transcripts.

In contrast to evidence that juvenile stress may lead to adaptive physiological changes in adult life that increase survival (Wang et al., 2016a; Wang et al., 2016b), we found that sublethal stress in the form of Varroa parasitism and oxidative stressinducing pesticide exposure decreases subsequent survival. Our results are consistent with previous reports that Varroa shortens the life of parasitized workers (De Jong et al., 1982; Schneider and Drescher, 1987). Our results also conform to the general consensus that pesticide exposure shortens lifespan (Gill et al., 2012; Retschnig et al., 2015; Wu et al., 2011), although a hormetic response to some xenobiotics has been 
reported that may increase resistance of honey bees to subsequent pesticide exposure (Mao et al., 2013; Schmehl et al., 2014). Together, our and previous findings suggest that the effect of early life stressors in honey bees is often detrimental and potential benefits may be restricted to specific stressors and doses (Calabrese and Baldwin, 2003).

The mortality risk of honey bee workers is closely associated with the workers' transition from in-hive task to outside foraging (Rueppell et al., 2007). Accordingly, the group differences of mortality and age of first foraging paralleled each other and the strongest stress effects on mortality were observed during the age when workers transitioned to foraging. However, mite-parasitized individuals exhibited a higher mortality even before the main onset of foraging in both experiments. The early deaths may be due to premature foraging attempts by some individuals (Perry et al., 2015), unnoticed in-hive deaths, or altruistic self-removal from the hive (Rueppell et al., 2010).

The simultaneous analyses of behavioral and treatment effects on mortality confirmed the life-shortening impact of Varroa parasitism independent of behavioral changes. The results also suggested that several behavioral categories performed by workers influence their likelihood of death (Dixon et al., 2014). However, some of these influences are counterintuitive. For example, "foraging" and the related "runway" behavior were associated with lower mortality, contrary to previous findings (Neukirch, 1982; Rueppell et al., 2007). The coincidence between the initiation of foraging and a noticeable increase of mortality rate in both experiments also contradicts the association between foraging-related activities and low mortality. The association may be a spurious result of our analysis because workers have mature and to live to a certain age to 
initiate foraging. Our separate analysis of the effects of early life behavior on subsequent mortality did not suffer from such problems. This "predictive behavioral demography" analysis resulted in more consistent findings: Two factors that were associated with the transition to foraging ("dance" and "runway") increased the subsequent mortality dramatically, corroborating previous evidence of the life-shortening influence of the life history transition to foraging (Rueppell et al., 2007).

Most transcript levels were affected by age, while treatment did not significantly affect any transcript levels in the young or the old age group. This result was paralleled by the measures of lipid oxidation, which also indicated a difference among age groups but no treatment effect. The lack of treatment effect suggests that any oxidative stress induced by Varroa mite parasitism or topical paraquat application did not affect the thorax or was repaired subsequently. As the site of intense metabolism, the honey bee thorax may be particularly well-protected against oxidative stress (Li-Byarlay et al., 2016). Nevertheless, the overall decline of oxidative damage with age was contrary to our prediction and the general observation that oxidative damage accumulates with age (Mecocci et al., 1999). Measures of oxidative damage in honey bees are rare and suggest that oxidative damage does not accumulate with age but depends on behavioral status (Seehuus et al., 2006a) and caste (Corona et al., 2007). The young individuals were sampled as nurses and most of our old cohort consisted of foragers. A similar decline of oxidative damage from nurses to foragers was observed in experimental cohorts that experienced migratory stress as brood (Simone-Finstrom et al., 2016). These findings may be explained by increased oxidative stress defenses in older bees, as suggested by high catalase and mGST1 transcript levels in our old bees. 
Another plausible explanation for the lower levels of oxidative damage in older individuals is selective mortality. The individuals surviving to advanced ages may be more-resistant and less-damaged individuals, consequently their lipid peroxidation measures are lower. Our first sample was taken when $74 \%$ of the experimental cohort was alive, while the second sample represented the last surviving $12 \%$. The mean oxidative damage of the old cohort was $63 \%$ of the corresponding value in the young cohort, less than one standard deviation apart. Thus, it would be possible to explain our observation with selective mortality of the individuals with high oxidative damage, although such selective mortality seems not to occur in captive male honey bees ( $\mathrm{Li}$ Byarlay et al., 2016). In free-flying worker honey bees, the argument of demographic selection is particularly compelling because the individuals' transition to riskier foraging tasks depends on their residual lifespan (Woyciechowski and Moron, 2009). Individuals that incur little damage when young may remain in the protected nest environment and survive to old age without large amounts of oxidative damage (Münch et al., 2013).

Similar to the decrease in oxidative damage with age, the age-related decline of deformed wing virus levels was not predicted. Although all studied individuals were asymptomatic, considerable amounts of DWV were detected, predominantly in the younger cohort. The lower DWV levels in the older cohort may also be due to demographic selection and selective mortality of the infected individuals, presumably due to an earlier onset of foraging (Woyciechowski and Moron, 2009), or altruistic selfremoval (Rueppell et al., 2010). Alternatively, older foraging workers may have lower DWV titers because they can fight infections and are further removed from the reinfection cycles of horizontal DWV transmission inside the brood nest (Möckel et al., 
2011). To our knowledge, no longitudinal studies exist in honey bees that evaluate the potential to clear viral infections or characterize the temporal dynamics of viral infections across different ages in individual honey bee workers.

The mRNA for the immune gene prophenol oxidase activator was less abundant in older than younger individuals, which contrasts with higher measurements of phenoloxidase activity in foragers than newly emerged workers (Wilson-Rich et al., 2008). The difference may be due to non-linear temporal dynamics in the humoral immune defense of honey bees (Schmid et al., 2008) or differences between enzymatic activity and expression. The remaining differences in transcript levels that were identified between the young and older cohorts conformed to predictions derived from the literature. Most oxidative stress defenses in worker honey bees were upregulated with age, presumably as a function of the metabolically intensive flight (Williams et al., 2008). Specifically, catalase and mGST1 have been found to be upregulated with honey bee worker age before (Corona et al., 2005). The declining expression of vitellogenin has also been reported, which is significant because vitellogenin serves as an antioxidant (Corona et al., 2007; Seehuus et al., 2006b), relates to nutrient status (Corona et al., 2007; Guidugli et al., 2005), and contributes to immunity (Amdam et al., 2005; Amdam et al., 2004b).

The lack of a long-term effect of treatment on the level of any of the investigated transcripts was not predicted. Varroa parasitism and associated viruses affect the honey bee immunity in complex ways (Di Prisco et al., 2016; Kuster et al., 2014) and a longterm suppression of some immune genes had previously been observed (Yang and Cox-Foster, 2005). Varroa parasitism decreases vitellogenin protein titers in the 
hemolymph of worker honey bees throughout adult life (Amdam et al., 2004a), which contrasts with our results. However, vitellogenin protein titers in the hemolymph might be independent of mRNA levels in the abdomen. Similarly to Varroa exposure, several pesticides show immediate effects on gene expression in developing honey bees (Gregorc et al., 2012), but our results suggest that these changes may not persist into adulthood.

Behavior and mortality are complex traits that are influenced by numerous factors beyond experimental control. Even molecular measures of oxidative damage and the immune system are influenced by many external factors, such as nutrition (Alaux et al., 2010; Simone-Finstrom et al., 2016) that are difficult to control under semi-natural conditions. Thus, varying results among independent experiments are not uncommon (Retschnig et al., 2015). Mortality dynamics were more consistent than molecular and behavioral outcomes, indicating that life-time mortality patterns represent an important measure in a variety of experimental contexts. No evidence was found that our stressors specifically affected late-life mortality or senescence, which may be due to social buffering of early life stress effects in social species (Wu-Smart and Spivak,

2016) and small sample sizes to estimate mortality rates at advanced ages.

Furthermore, our results corroborate the importance of social behavior in the determination of the lifespan of honey bee workers (Rueppell et al., 2007) and other social species.

\section{Acknowledgements}

We would like to acknowledge the help of Hongmei Li-Byarlay for training and guidance on the TBARS assay, Kaira Wagoner for guiding us in Varroa mite handling, 
Humberto Boncristiani for help with the gene expression assays, and beekeeper Robert Jacobs volunteering his hives as sources for some of the Varroa mites. We also would like to thank all members of the UNCG Social Insect Lab for their support and encouragement. The work was funded by the National Institutes of Health (NIA grant R21AG046837), USDA-NIFA (grant \#2010-65104-20533), and the Army Research Office (grant W911NF-15-2-0045). The authors declare no conflicts of interest.

\section{Data Access}

All raw data are available as online supplements. S1: Behavioral and demographic data. S2: Relative gene expression data and results of the TBARS assay.

\section{References}

Alaux, C., Ducloz, F., Crauser, D., Le Conte, Y., 2010. Diet effects on honeybee immunocompetence. Biology Letters 6, 562-565.

Amdam, G. V., 2011. Social context, stress, and plasticity of aging. Aging Cell 10, 1827.

Amdam, G. V., Hartfelder, K., Norberg, K., Hagen, A., Omholt, S. W., 2004a. Altered physiology in worker honey bees (Hymenoptera : Apidae) infested with the mite Varroa destructor (Acari : Varroidae): A factor in colony loss during overwintering? Journal of Economic Entomology 97, 741-747.

Amdam, G. V., Aase, A. L. T. O., Seehuus, S. C., Fondrk, M. K., Norberg, K., Hartfelder, K., 2005. Social reversal of immunosenescence in honey bee workers. Experimental Gerontology 40, 939-947.

Amdam, G. V., Simoes, Z. L. P., Hagen, A., Norberg, K., Schroder, K., Mikkelsen, O., Kirkwood, T. B. L., Omholt, S. W., 2004b. Hormonal control of the yolk precursor vitellogenin regulates immune function and longevity in honeybees. Experimental Gerontology 39, 767-773. 
Beldade, P., Mateus, A. R. A., Keller, R. A., 2011. Evolution and molecular mechanisms of adaptive developmental plasticity. Molecular Ecology 20, 1347-1363.

Boncristiani, H. F., Evans, J. D., Chen, Y., Pettis, J., Murphy, C., Lopez, D. L., SimoneFinstrom, M. D., Strand, M., Tarpy, D. R., Rueppell, O., 2013. In-vitro infection of pupae with Israeli Acute Paralysis Virus suggests variation for susceptibility and disturbance of transcriptional homeostasis in honey bees (Apis mellifera). PLoS One 8, e73429.

Bus, J. S., Gibson, J. E., 1984. Paraquat - model for oxidant-initiated toxicity. Environmental Health Perspectives 55, 37-46.

Calabrese, E. J., Baldwin, L. A., 2003. Hormesis: the dose-response revolution. Annual Review of Pharmacology and Toxicology 43, 175-197.

Colborn, T., vom Saal, F. S., Soto, A. M., 1993. Developmental effects of endocrinedisrupting chemicals in wildlife and humans. Environmental Health Perspectives 101, 378-384.

Cornman, R. S., Tarpy, D. R., Chen, Y., Jeffreys, L., Lopez, D., Pettis, J. S., vanEngelsdorp, D., Evans, J. D., 2012. Pathogen webs in collapsing honey bee colonies. PLoS One 7, e43562.

Corona, M., Robinson, G. E., 2006. Genes of the antioxidant system of the honey bee: annotation and phylogeny. Insect Molecular Biology 15, 687-701.

Corona, M., Hughes, K. A., Weaver, D. B., Robinson, G. E., 2005. Gene expression patterns associated with queen honey bee longevity. Mechanisms of Ageing and Development 126, 1230-1238.

Corona, M., Velarde, R. A., Remolina, S., Moran-Lauter, A., Wang, Y., Hughes, K. A., Robinson, G. E., 2007. Vitellogenin, juvenile hormone, insulin signaling, and queen honey bee longevity. Proceedings of the National Academy of Sciences of the United States of America 104, 7128-7133.

De Jong, D., De Jong, P., Goncalves, L., 1982. Weight loss and other damage to developing worker honeybees from infestation with Varroa jacobsoni. Journal of Apicultural Research 21, 165-167.

Desneux, N., Decourtye, A., Delpuech, J. M., 2007. The sublethal effects of pesticides on beneficial arthropods. Annual Review of Entomology 52, 81-106. 
Di Prisco, G., Annoscia, D., Margiotta, M., Ferrara, R., Varricchio, P., Zanni, V., Caprio, E., Nazzi, F., Pennacchio, F., 2016. A mutualistic symbiosis between a parasitic mite and a pathogenic virus undermines honey bee immunity and health.

Proceedings of the National Academy of Sciences 113, 3203-3208.

Dietemann, V., Nazzi, F., Martin, S. J., Anderson, D. L., Locke, B., Delaplane, K. S., Wauquiez, Q., Tannahill, C., Frey, E., Ziegelmann, B., 2013. Standard methods for Varroa research. Journal of Apicultural Research 52, 1-54.

Dietemann, V., Pflugfelder, J., Anderson, D., Charrière, J. D., Chejanovsky, N., Dainat, B., De Miranda, J., Delaplane, K., Dillier, F. X., Fuch, S., Gallmann, P., Gauthier, L., Imdorf, A., Koeniger, N., Kralj, J., Meikle, W., Pettis, J., Rosenkranz, P., Sammataro, D., Smith, D., Yanez, O., Neumann, P., 2012. Varroa destructor: Research avenues towards sustainable control. Journal of Apicultural Research 51, 125-132.

Dixon, L., Kuster, R., Rueppell, O., 2014. Reproduction, social behavior, and aging trajectories in honeybee workers. Age (Dordr) 36, 89-101.

Evans, J. D., 2006. Beepath: an ordered quantitative-PCR array for exploring honey bee immunity and disease. Journal of Invertebrate Pathology 93, 135-139.

Genersch, E., Aubert, M., 2010. Emerging and re-emerging viruses of the honey bee (Apis mellifera L.). Veterinary Research 41, 54.

Gill, R. J., Ramos-Rodriguez, O., Raine, N. E., 2012. Combined pesticide exposure severely affects individual- and colony-level traits in bees. Nature 491, 105-108.

Gluckman, P. D., Hanson, M. A., Spencer, H. G., 2005. Predictive adaptive responses and human evolution. Trends in Ecology \& Evolution 20, 527-533.

Gregorc, A., Evans, J. D., Scharf, M., Ellis, J. D., 2012. Gene expression in honey bee (Apis mellifera) larvae exposed to pesticides and Varroa mites (Varroa destructor). Journal of Insect Physiology 58, 1042-1049.

Guidugli, K. R., Nascimento, A. M., Amdam, G. V., Barchuk, A. R., Omholt, S., Simoes, Z. L. P., Hartfelder, K., 2005. Vitellogenin regulates hormonal dynamics in the worker caste of a eusocial insect. Febs Letters 579, 4961-4965.

Hales, C. N., Barker, D. J. P., 2001. The thrifty phenotype hypothesis. British Medical Bulletin 60, 5-20. 
Huang, Z., 2012. Pollen nutrition affects honey bee stress resistance. Terrestrial Arthropod Reviews 5, 175-189.

Janmaat, A., Winston, M., 2000. The influence of pollen storage area and Varroa jacobsoni Oudemans parasitism on temporal caste structure in honey bees (Apis mellifera L.). Insectes Sociaux 47, 177-182.

Kielmanowicz, M. G., Inberg, A., Lerner, I. M., Golani, Y., Brown, N., Turner, C. L., Hayes, G. J., Ballam, J. M., 2015. Prospective large-scale field study generates predictive model identifying major contributors to colony losses. PLoS Pathog 11, e1004816.

Kralj, J., Brockmann, A., Fuchs, S., Tautz, J., 2007. The parasitic mite Varroa destructor affects non-associative learning in honey bee foragers, Apis mellifera L. Journal of Comparative Physiology A 193, 363-370.

Kuster, R. D., Boncristiani, H. F., Rueppell, O., 2014. Immunogene and viral transcript dynamics during parasitic Varroa destructor mite infection of developing honey bee (Apis mellifera) pupae. Journal of Experimental Biology 217, 1710-1718.

Li-Byarlay, H., Huang, M. H., Simone-Finstrom, M. D., Strand, M. K., Tarpy, D. R., Rueppell, O., 2016. Honey bee (Apis mellifera) drones survive oxidative stress due to increased tolerance instead of avoidance or repair of oxidative damage. Experimental Gerontology 83, 15-21.

Mao, W., Schuler, M. A., Berenbaum, M. R., 2013. Honey constituents up-regulate detoxification and immunity genes in the western honey bee Apis mellifera. Proceedings of the National Academy of Sciences 110, 8842-8846.

Martin, S. J., Highfield, A. C., Brettell, L., Villalobos, E. M., Budge, G. E., Powell, M., Nikaido, S., Schroeder, D. C., 2012. Global honey bee viral landscape altered by a parasitic mite. Science 336, 1304-1306.

Mecocci, P., Fano, G., Fulle, S., MacGarvey, U., Shinobu, L., Polidori, M. C., Cherubini, A., Vecchiet, J., Senin, U., Beal, M. F., 1999. Age-dependent increases in oxidative damage to DNA, lipids, and proteins in human skeletal muscle. Free Radical Biology and Medicine 26, 303-308. 
Möckel, N., Gisder, S., Genersch, E., 2011. Horizontal transmission of deformed wing virus: pathological consequences in adult bees (Apis mellifera) depend on the transmission route. Journal of General Virology 92, 370-377.

Mullin, C. A., Frazier, M., Frazier, J. L., Ashcraft, S., Simonds, R., vanEngelsdorp, D., Pettis, J. S., 2010. High levels of miticides and agrochemicals in North American apiaries: Implications for honey bee health. PLoS One 5, e9754.

Münch, D., Kreibich, C. D., Amdam, G. V., 2013. Aging and its modulation in a longlived worker caste of the honey bee. Journal of Experimental Biology 216, 16381649.

Neukirch, A., 1982. Dependence of the life-span of the honeybee (Apis mellifica) upon flight performance and energy-consumption. Journal of Comparative Physiology 146, 35-40.

Pabinger, S., Rödiger, S., Kriegner, A., Vierlinger, K., Weinhäusel, A., 2014. A survey of tools for the analysis of quantitative PCR (qPCR) data. Biomolecular Detection and Quantification 1, 23-33.

Perry, C. J., Søvik, E., Myerscough, M. R., Barron, A. B., 2015. Rapid behavioral maturation accelerates failure of stressed honey bee colonies. Proceedings of the National Academy of Sciences 112, 3427-3432.

Pettis, J. S., vanEngelsdorp, D., Johnson, J., Dively, G., 2012. Pesticide exposure in honey bees results in increased levels of the gut pathogen Nosema. Naturwissenschaften 99, 153-158.

Retschnig, G., Williams, G. R., Odemer, R., Boltin, J., Di Poto, C., Mehmann, M. M., Retschnig, P., Winiger, P., Rosenkranz, P., Neumann, P., 2015. Effects, but no interactions, of ubiquitous pesticide and parasite stressors on honey bee (Apis mellifera) lifespan and behaviour in a colony environment. Environmental Microbiology 17, 4322-4331.

Roseboom, T., de Rooij, S., Painter, R., 2006. The Dutch famine and its long-term consequences for adult health. Early Human Development 82, 485-491.

Rosenkranz, P., Aumeier, P., Ziegelmann, B., 2010. Biology and control of Varroa destructor. Journal of Invertebrate Pathology 103 Suppl 1, S96-119. 
Rueppell, O., Hayworth, M. K., Ross, N. P., 2010. Altruistic self-removal of healthcompromised honey bee workers from their hive. Journal of Evolutionary Biology 23, 1538-1546.

Rueppell, O., Bachelier, C., Fondrk, M. K., Page Jr, R. E., 2007. Regulation of life history determines lifespan of worker honey bees (Apis mellifera L.). Experimental Gerontology 42, 1020-1032.

Sánchez-Bayo, F., Goulson, D., Pennacchio, F., Nazzi, F., Goka, K., Desneux, N., 2016. Are bee diseases linked to pesticides?-A brief review. Environment International 89, 7-11.

Scharlaken, B., de Graaf, D. C., Goossens, K., Brunain, M., Peelman, L. J., Jacobs, F. J., 2008. Reference gene selection for insect expression studies using quantitative real-time PCR: The head of the honeybee, Apis mellifera, after a bacterial challenge. Journal of Insect Science 8, 33.

Schmehl, D. R., Teal, P. E., Frazier, J. L., Grozinger, C. M., 2014. Genomic analysis of the interaction between pesticide exposure and nutrition in honey bees (Apis mellifera). Journal of Insect Physiology 71, 177-190.

Schmid, M. R., Brockmann, A., Pirk, C. W., Stanley, D. W., Tautz, J., 2008. Adult honeybees (Apis mellifera L.) abandon hemocytic, but not phenoloxidase-based immunity. Journal of Insect Physiology 54, 439-444.

Schneider, P., Drescher, W., 1987. Einfluss der Parasitierung durch die Milbe Varroa jacobsoni Oud. aud das Schlupfgewicht, die Gewichtsentsicklung, die Entwicklung der Hypopharynxdrüsen und die Lebensdauer von Apis mellifera L. Apidologie 18, 101-110.

Seehuus, S.-C., Krekling, T., Amdam, G. V., 2006a. Cellular senescence in honey bee brain is largely independent of chronological age. Experimental Gerontology 41, 1117-1125.

Seehuus, S. C., Norberg, K., Gimsa, U., Krekling, T., Amdam, G. V., 2006b. Reproductive protein protects sterile honey bee workers from oxidative stress. Proceedings of the National Academy of Sciences 103, 962-967. 
Simone-Finstrom, M., Li-Byarlay, H., Huang, M. H., Strand, M. K., Rueppell, O., Tarpy, D. R., 2016a. Migratory management and environmental conditions affect lifespan and oxidative stress in honey bees. Scientific Reports 6, 32023.

Turner, J. S., 2009. The extended organism: the physiology of animal-built structures. Harvard University Press.

Wang, Y., Kaftanoglu, O., Brent, C. S., Page, R. E., Amdam, G. V., 2016a. Starvation stress during larval development facilitates an adaptive response in adult worker honey bees (Apis mellifera L.). Journal of Experimental Biology 219, 949-959.

Wang, Y., Campbell, J. B., Kaftanoglu, O., Page, R. E., Amdam, G. V., Harrison, J. F., 2016b. Larval starvation improves metabolic response to adult starvation in honey bees (Apis mellifera L.). Journal of Experimental Biology 219, 960-968.

Williams, J. B., Roberts, S. P., Elekonich, M. M., 2008. Age and natural metabolicallyintensive behavior affect oxidative stress and antioxidant mechanisms. Experimental Gerontology 43, 538-549.

Wilson-Rich, N., Dres, S. T., Starks, P. T., 2008. The ontogeny of immunity: Development of innate immune strength in the honey bee (Apis mellifera). Journal of Insect Physiology 54, 1392-1399.

Wilson, E. O., 1971. The Insect Societies. The Belknap Press of Harvard University Press, Cambridge, Mass.

Winston, M. L., 1987. The Biology of the Honey Bee. Harvard University Press, Cambridge, Massachusetts.

Woyciechowski, M., Moron, D., 2009. Life expectancy and onset of foraging in the honeybee (Apis mellifera). Insectes Sociaux 56, 193-201.

Wu-Smart, J., Spivak, M., 2016. Sub-lethal effects of dietary neonicotinoid insecticide exposure on honey bee queen fecundity and colony development. Scientific Reports 6, 32108.

Wu, J. Y., Anelli, C. M., Sheppard, W. S., 2011. Sub-lethal effects of pesticide residues in brood comb on worker honey bee (Apis mellifera) development and longevity. PLoS One 6, e14720. 
Yang, X., Cox-Foster, D. L., 2005. Impact of an ectoparasite on the immunity and pathology of an invertebrate: evidence for host immunosuppression and viral amplification. Proceedings of the National Academy of Sciences 102, 7470-7475.

\section{Figure Legends}

Figure 1: Cumulative survival of adult honey bee workers that were stressed by Varroa mite parasitism during development or not (controls) in the first experiment. The insert depicts the corresponding transition from in-hive tasks to foraging (AFF) in both experimental groups.

Figure 2: Cumulative survival of adult honey bee workers that were stressed by Varroa mite parasitism during development, paraquat exposed upon emergence, or intact controls in the second experiment. The insert depicts the corresponding transition from in-hive tasks to foraging (AFF) in the three experimental groups.

Figure 3: Changes in relative transcript levels in experimental bees with age. While treatment did not significantly affect any transcript at either age, catalase, deformed wing virus (DWV), microsomal glutathione-S-transferase (mGST1), prophenol oxidase activator (PPOact), and vitellogenin $(\mathrm{Vg})$ were significantly different between age groups. $\Delta \mathrm{Ct}$ values were calculated as $\mathrm{Ct}$ (reference) $-\mathrm{Ct}$ (target), so that a high value corresponds to a relatively high target expression. Sample sizes were as follows: $\mathrm{N}($ young $)=34, \mathrm{~N}($ old $)=45$. 


\section{Tables}

Table 1: Categories to Characterize Honey Bee Worker Behavior with Definitions

\begin{tabular}{ll} 
Behavior & Definition \\
\hline Cleaning & Direct contact of mouthparts and cell or other nest component \\
Brood Care & Feeding, cleaning or investigating brood, or patrolling over brood area \\
Queen Tending & Direct contact with queen, antennating, cleaning, or feeding her \\
Nectar Processing & Exchanging food via trophallaxis or depositing nectar into cells \\
Pollen Processing & Depositing or manipulating pollen freely or in pollen cells \\
Comb Building & Wax manipulation and deposition, including capping cells \\
Ventilation & Fanning wings inside the hive \\
Patrolling & Undirected movement, investigating, and other miscellaneous \\
Resting & Individual motionless for more than three seconds \\
Guarding & Oriented near the hive entrance, inspecting incoming bees \\
Grooming & Prolonged antennation and cleaning of self or other workers or drones \\
Dance & Waggle or round dancing or following such dances \\
Runway & Stationary in the wooden passage between comb and hive exit \\
Foraging & Hive entry with visible pollen or directed move toward unloading \\
\hline
\end{tabular}

Table 2: Transcripts Evaluated by qPCR with Primer Information

\begin{tabular}{llll} 
Name & \multicolumn{2}{l}{$\begin{array}{l}\text { NCBI Gene-ID } \\
\text { or Accession }\end{array}$} & \\
& 406122 & TTGTATGCCAACAC Primer \\
\hline Actin & 443552 & GTCTTGGCCCAAACAATCTG & CATTCTCTAGGCCCACCAAA \\
Catalase & AY292384.1 & GAGATTGAAGCGCATGAACA & TGAATTCAGTGTCGCCCATA \\
DWV & 406142 & CTCTTCTGTGCCGTTGCATA & GCGTCTCCTGTCATTCCATT \\
Hymenoptaecin & 102655694 & AAGTGAAGAATAATGGTGGCTAC & CAGAATGTGGACGCTTATCAAG \\
mGST1 & 726126 & GTTTGGTCGACGGAAGAAAA & CCGTCGACTCGAAATCGTAT \\
PPOact & 409398 & GTCGTTCCGTGTAGTCGAGAA & TCCTTTGACTTCACCCTGAAGA \\
SOD1 & 406088 & AGTTCCGACCGACGACGA & TTCCCTCCCACGGAGTCC \\
Vg & & &
\end{tabular}


Table 3: Factors in the final logistic regression models of the effects of treatment and behavior on individual worker mortality in both experimental trials

\begin{tabular}{lll} 
Factor & Hazard Ratio $(95 \% \mathrm{Cl})$ & Significance \\
\hline Trial 1 & & \\
Treatment (mite) & $1.87(1.33-2.62)$ & $\mathrm{p}<0.001$ \\
Brood care & $38.7(10.3-145.4)$ & $\mathrm{p}<0.001$ \\
Comb building & $84.5(4.04-1770)$ & $\mathrm{p}=0.004$ \\
Resting & $4.0(0.84-18.7)$ & $\mathrm{p}=0.082$ \\
Ventilation & $11.5(1.02-130.6)$ & $\mathrm{p}=0.048$ \\
Grooming & $4.9(1.20-20.1)$ & $\mathrm{p}=0.027$ \\
Foraging & $0.001(0.000-0.56)$ & $\mathrm{p}=0.032$ \\
\hline Trial 2 & & \\
Treatment (mite) & $1.55(1.06-2.27)$ & $\mathrm{p}=0.025$ \\
Comb building & $0.000(0.000-0.000)$ & $\mathrm{p}<0.001$ \\
Resting & $0.07(0.02-0.23)$ & $\mathrm{p}<0.001$ \\
Nectar processing & $55.7(1.05-2955)$ & $\mathrm{p}=0.047$ \\
Runway & $0.001(0.000-0.015)$ & $\mathrm{p}<0.001$ \\
Foraging & $0.000(0.000-0.041)$ & $\mathrm{p}=0.022$ \\
\hline
\end{tabular}


Table 4: Gene expression comparisons among young and old stressed and control workers

\begin{tabular}{|c|c|c|c|c|c|c|}
\hline Transcript & $\begin{array}{l}\text { Treatment } \\
\text { Effect }\end{array}$ & Age Effect & $\begin{array}{l}\text { Interaction } \\
\text { Effect }\end{array}$ & $\begin{array}{l}\text { Average* } \\
\Delta \mathrm{Ct} \pm \text { S.D. }\end{array}$ & Young & Old \\
\hline DWV & $\begin{array}{l}F_{(2,65)}=2.0, \\
p=0.140\end{array}$ & $\begin{array}{l}F_{(1,65)}=58.4, \\
p<0.001\end{array}$ & $\begin{array}{l}F_{(2,65)}=0.9 \\
p=0.408\end{array}$ & $\begin{array}{l}\text { Control: } \\
\text { Varroa: } \\
\text { Paraquat: }\end{array}$ & $\begin{array}{l}-7.3( \pm 5.6) \\
-9.0( \pm 6.1) \\
-4.7( \pm 4.4)\end{array}$ & $\begin{array}{l}-14.7( \pm 2.4) \\
-15.9( \pm 3.8) \\
-14.7( \pm 3.6)\end{array}$ \\
\hline Catalase & $\begin{array}{l}F_{(2,70)}=2.4 \\
p=0.097\end{array}$ & $\begin{array}{l}F_{(1,70)}=54.7 \\
p<0.001\end{array}$ & $\begin{array}{l}F_{(2,70)}=0.9, \\
p=0.690\end{array}$ & $\begin{array}{l}\text { Control: } \\
\text { Varroa: } \\
\text { Paraquat: }\end{array}$ & $\begin{array}{l}-7.0( \pm 2.1) \\
-8.4( \pm 1.2) \\
-7.6( \pm 2.3)\end{array}$ & $\begin{array}{l}-4.6( \pm 1.2) \\
-5.4( \pm 1.1) \\
-4.4( \pm 0.8)\end{array}$ \\
\hline mGST1 & $\begin{array}{l}F_{(2,73)}=1.3, \\
p=0.266\end{array}$ & $\begin{array}{l}F_{(1,73)}=19.7 \\
p<0.001\end{array}$ & $\begin{array}{l}F_{(2,73)}=0.0, \\
p=0.994\end{array}$ & $\begin{array}{l}\text { Control: } \\
\text { Varroa: } \\
\text { Paraquat: }\end{array}$ & $\begin{array}{l}-5.6( \pm 4.6) \\
-6.5( \pm 5.3) \\
-4.8( \pm 3.9)\end{array}$ & $\begin{array}{l}-1.9( \pm 2.2) \\
-2.7( \pm 3.0) \\
-0.9( \pm 2.5)\end{array}$ \\
\hline Vg & $\begin{array}{l}F_{(2,66)}=0.4 \\
p=0.669\end{array}$ & $\begin{array}{l}F_{(1,66)}=9.6 \\
p=0.003\end{array}$ & $\begin{array}{l}F_{(2,66)}=0.6, \\
p=0.567\end{array}$ & $\begin{array}{l}\text { Control: } \\
\text { Varroa: } \\
\text { Paraquat: }\end{array}$ & $\begin{array}{l}-3.5( \pm 3.7) \\
-4.3( \pm 1.6) \\
-5.1( \pm 2.7)\end{array}$ & $\begin{array}{l}-7.7( \pm 3.7) \\
-6.4( \pm 5.7) \\
-7.5( \pm 3.7)\end{array}$ \\
\hline PPOact & $\begin{array}{l}F_{(2,60)}=0.2 \\
p=0.812\end{array}$ & $\begin{array}{l}F_{(1,60)}=4.3 \\
p=0.042\end{array}$ & $\begin{array}{l}F_{(2,60)}=0.6 \\
p=0.526\end{array}$ & $\begin{array}{l}\text { Control: } \\
\text { Varroa: } \\
\text { Paraquat: }\end{array}$ & $\begin{array}{l}-9.8( \pm 3.8) \\
-9.0( \pm 4.4) \\
-6.9( \pm 12.8)\end{array}$ & $\begin{array}{l}-11.9( \pm 2.4) \\
-11.8( \pm 3.0) \\
-12.7( \pm 3.8)\end{array}$ \\
\hline $\begin{array}{l}\text { Hymenop- } \\
\text { taecin }\end{array}$ & $\begin{array}{l}F_{(2,60)}=0.6, \\
p=0.555\end{array}$ & $\begin{array}{l}F_{(1,60)}=1.7 \\
p=0.204\end{array}$ & $\begin{array}{l}F_{(2,60)}=0.3 \\
p=0.733\end{array}$ & $\begin{array}{l}\text { Control: } \\
\text { Varroa: } \\
\text { Paraquat: }\end{array}$ & $\begin{array}{l}-6.6( \pm 2.6) \\
-7.6( \pm 3.0) \\
-6.6( \pm 2.8)\end{array}$ & $\begin{array}{l}-6.1( \pm 3.0) \\
-6.2( \pm 5.7) \\
-4.4( \pm 5.0)\end{array}$ \\
\hline SOD1 & $\begin{array}{l}F_{(2,59)}=2.5 \\
p=0.087\end{array}$ & $\begin{array}{l}F_{(1,59)}=1.1 \\
p=0.289\end{array}$ & $\begin{array}{l}F_{(2,59)}=0.1 \\
p=0.924\end{array}$ & $\begin{array}{l}\text { Control: } \\
\text { Varroa: } \\
\text { Paraquat: }\end{array}$ & $\begin{array}{l}-1.7( \pm 1.8) \\
-2.8( \pm 1.6) \\
-2.5( \pm 1.7)\end{array}$ & $\begin{array}{l}-1.5( \pm 1.1) \\
-2.3( \pm 1.0) \\
-2.1( \pm 0.5)\end{array}$ \\
\hline
\end{tabular}

*Sample sizes: $\mathrm{N}$ (young, control) = 13, $\mathrm{N}$ (young, paraquat) $=14, \mathrm{~N}$ (young, Varroa) $=7, \mathrm{~N}$ (old, control $)=23, \mathrm{~N}$ (old, paraquat $)=15, \mathrm{~N}($ old, Varroa $)=7$. 


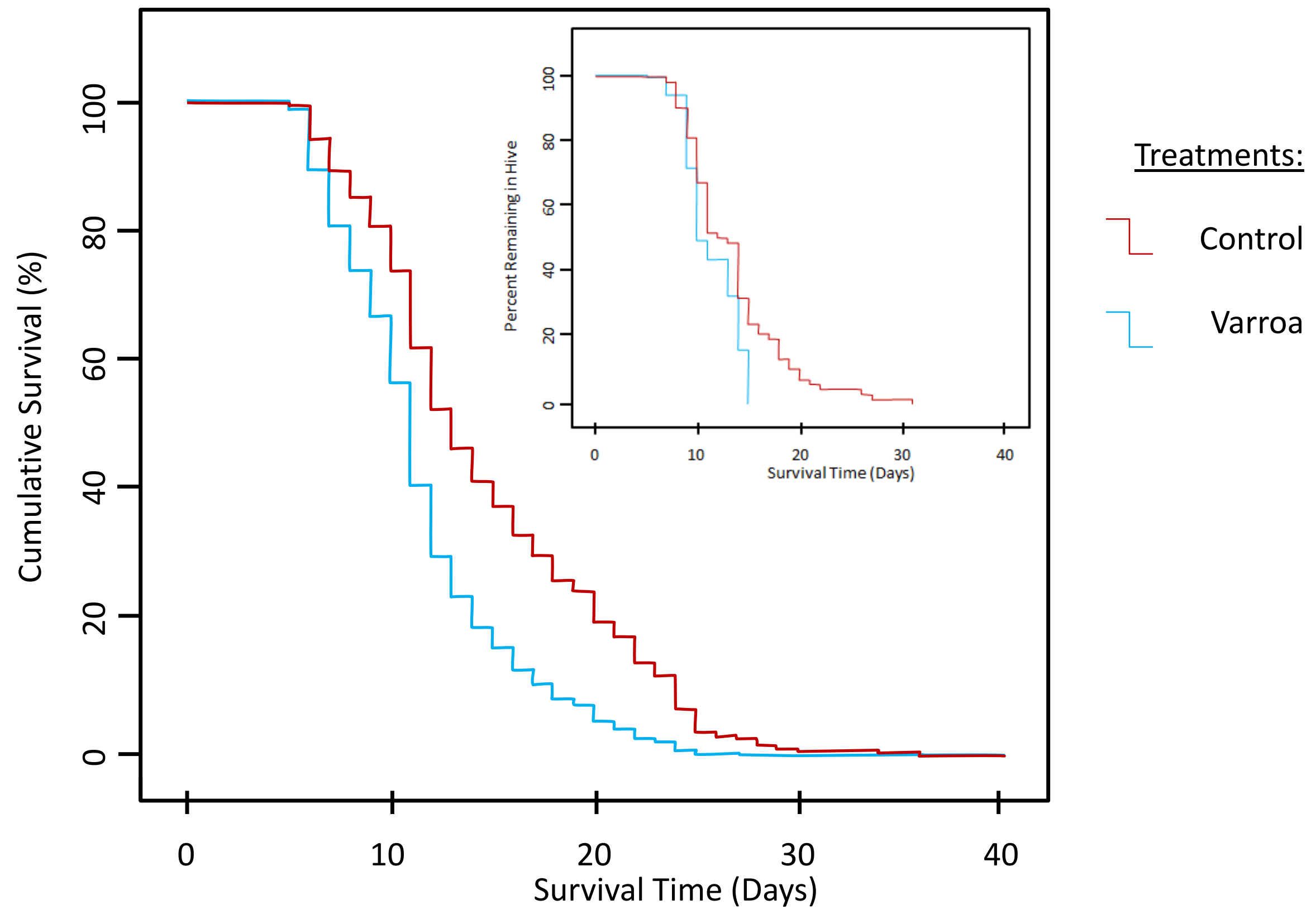




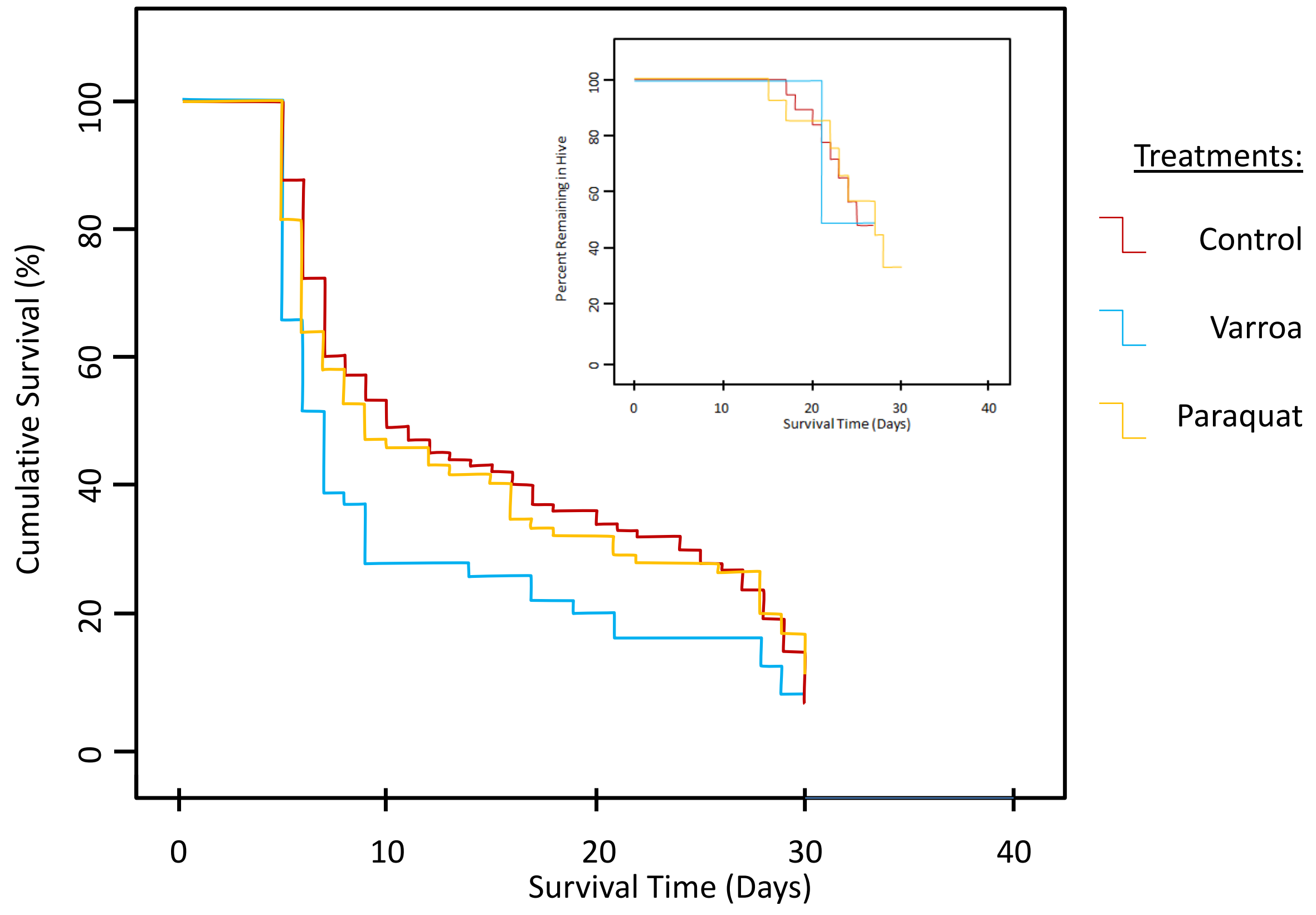




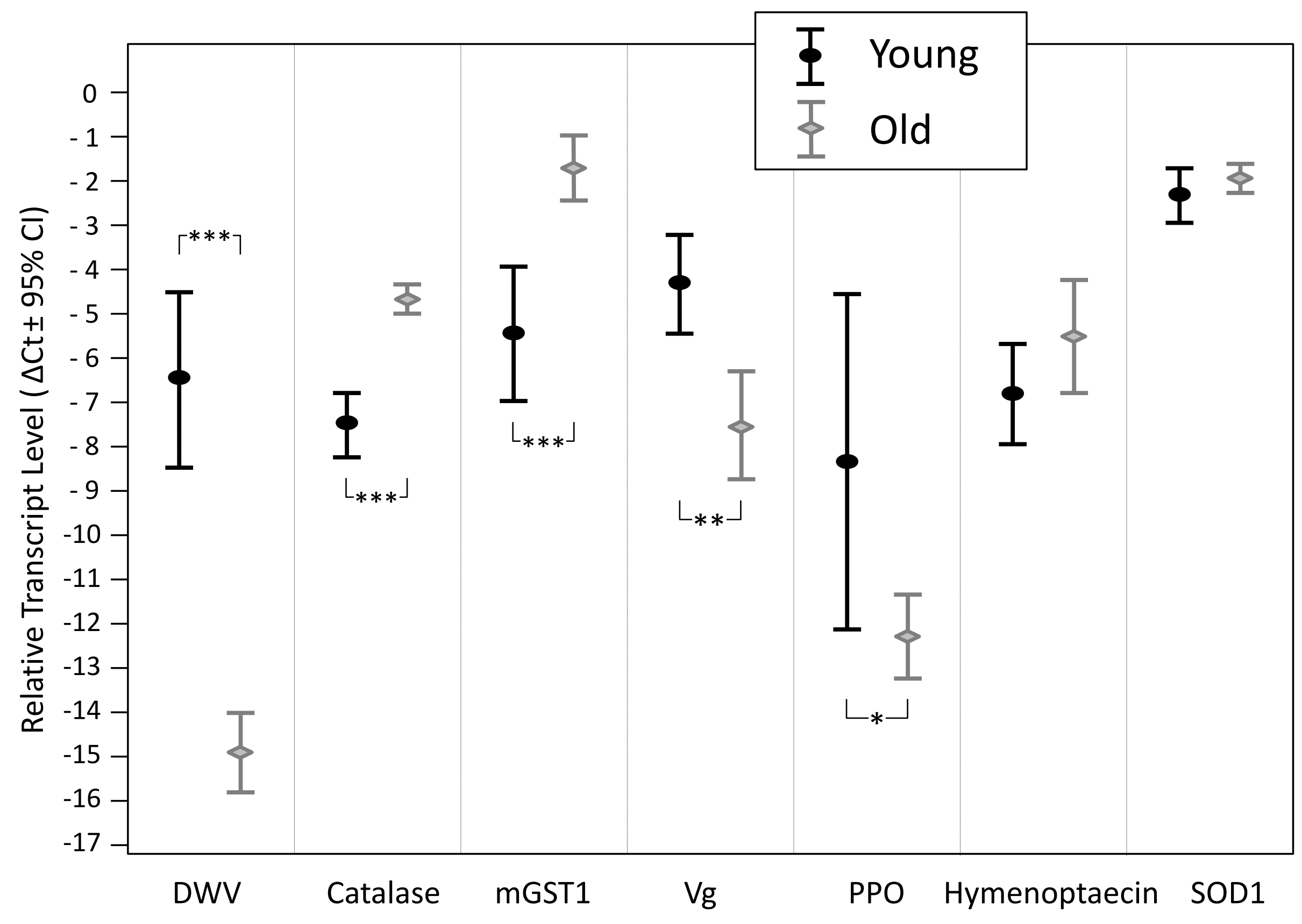

